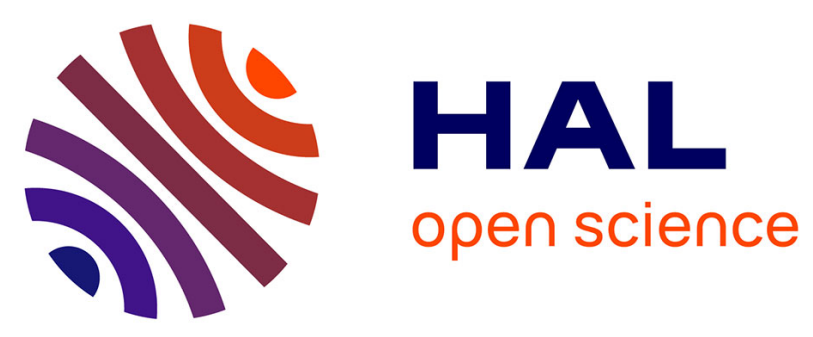

\title{
Investigating microbial associations from sequencing survey data with co-correspondence analysis
}

Benjamin Alric, Cajo J.F. ter Braak, Yves Desdevises, Hugo Lebredonchel, Stéphane Dray

\section{- To cite this version:}

Benjamin Alric, Cajo J.F. ter Braak, Yves Desdevises, Hugo Lebredonchel, Stéphane Dray. Investigating microbial associations from sequencing survey data with co-correspondence analysis. Molecular Ecology Resources, 2020, 20 (2), pp.468-480. 10.1111/1755-0998.13126 . hal-02400150

\section{HAL Id: hal-02400150 \\ https://univ-lyon1.hal.science/hal-02400150}

Submitted on 31 Dec 2020

HAL is a multi-disciplinary open access archive for the deposit and dissemination of scientific research documents, whether they are published or not. The documents may come from teaching and research institutions in France or abroad, or from public or private research centers.
L'archive ouverte pluridisciplinaire HAL, est destinée au dépôt et à la diffusion de documents scientifiques de niveau recherche, publiés ou non, émanant des établissements d'enseignement et de recherche français ou étrangers, des laboratoires publics ou privés. 


\section{Investigating microbial associations from sequencing survey data with}

\section{2 co-correspondence analysis}

3 Benjamin Alric $^{1^{*}}$, Cajo J.F. ter Braak ${ }^{2}$, Yves Desdevises ${ }^{3}$, Hugo Lebredonchel ${ }^{3}$, Stéphane

4 Dray $^{1}$

6 1'Université de Lyon, CNRS, UMR 5558, Laboratoire de Biométrie et Biologie Evolutive,

7 Université Lyon1, F-69622 Villeurbanne, France

8 '2Biometris, Wageningen University \& Research, Box 16, 6700 AA Wageningen, The

9 Netherlands

$10{ }^{3}$ Sorbonne Université, CNRS, UMR 7232, Biologie Intégrative des Organismes Marins, BIOM,

11 Observatoire Océanologique, F-66650 Banyuls sur Mer, France

$15{ }^{*}$ Corresponding author: Benjamin ALRIC, Irstea, UR RiverLy, Laboratoire

16 d'écotoxicologie, centre de Lyon-Villeurbanne, 5 rue de la Doua CS 20244, F-69625,

17 Villeurbanne, France. benjamin.alric@irstea.fr

19 'Current address: Irstea, UR RiverLy, Laboratoire d'écotoxicologie, centre de Lyon-

20 Villeurbanne, 5 rue de la Doua CS 20244, F-69625, Villeurbanne, France.

22 Keywords: co-correspondence analysis, co-occurrence network, next-generation

23 sequencing, microbial eukaryotes, Mamiellophyceae, Prasinovirus

25 Running tittle: Cross-taxon congruence in microbial communities 


\section{Abstract}

Microbial communities, which drive the major ecosystem functions, are

28 composed by a wide range of interacting species. Understanding how microbial

29 communities are structured and the underlying processes is a crucial task for

30 interpreting ecosystem response to global change but it is challenging as microbial

31 interactions cannot usually be directly observed. Multiple efforts are currently focused

32 to combine next-generation sequencing (NGS) techniques with refine $\underline{d}$ statistical

33 analysis (e.g., network analysis, multivariate analysis) to characterize the structures of

34 microbial communities. However, most of these approaches consider a single table of

35 sequencing data measured for several samples. Technological advances now make it

36 possible to collect NGS data on different taxonomic groups simultaneously for the same

37 samples and lead to analyze a pair of tables. Here, an analytic framework based on co-

38 correspondence analysis (CoCA) is proposed to study the distributions, assemblages and

39 interactions between two microbial communities. We showed the ability of this

40 approach to highlight the relationships between two microbial communities, using two

41 data sets exhibiting various types of interactions. CoCA identified strong association

42 patterns between autotrophic and heterotrophic microbial eukaryotes assemblages, on

43 one hand, and between microalgae and viruses, on the other hand. We demonstrate also

44 how CoCA can be used, in complement to network analysis, to reorder co-occurrence

45 networks and thus investigate the presence of patterns in ecological networks. 


\section{Introduction}

Microbial communities are highly diverse (Rappé \& Giovannoni, 2003) and drive the major ecosystem functions (e.g., carbon sequestration, climate regulation, gas

regulation, nutrient cycling; Ducklow, 2008; Falkowski, Fenchel, \& Delong, 2008;

50 Hutchins \& Fu, 2017). Understanding how these systems are structured and identifying

51 the underlying processes is a crucial task to predict communities and ecosystem

52 responses to global change (Fuhrman, 2009; Graham et al., 2016). Biotic interactions

53 across taxonomic groups (e.g., predation, parasitism, mutualism or competition) are of

54 broad interest because they are expected to influence the structure and composition of

55 communities (Wisz et al., 2013). Unfortunately, our understanding of the underlying

56 assemblage rules of microbial communities is still limited (Little et al., 2008; Cordero $\mathcal{E}$

57 Datta, 2016).

58 The emergence of high-throughput sequencing techniques (next-generation

59 sequencing; NGS) gave access to the diversity of whole microbial communities, including

60 the non-cultivable fraction (Handelsman, 2004; Zimmerman, Izard, Klatt, Zhou, \&

61 Aronson, 2014; Zinger, Gobet, \& Pommier, 2011). With the large amount of data

62 generated in a single NGS experiment, powerful statistical methods are needed to assess

63 and explain structural patterns in such complex data sets (Bálint et al., 2016; Paliy $\mathcal{E}$

64 Shankar, 2016). A common approach is to combine NGS techniques with network

65 analysis to represent and characterize interactions between partners in microbial

66 communities (Cardona, Weisenhorn, Henry, \& Gilbert, 2016; Vacher et al., 2016).

67 Various computational methods have been developed to infer networks from NGS data

68 sets (e.g., CoNet: Faust et al., 2012; SparCC: Friedman \& Alm, 2012; REBACCA: Ban, An, \&

69 Jiang, 2015; CCLasso: Fang, Huang, Zhao, \& Deng, 2015; SPIEC-EASI: Kurtz et al., 2015).

70 Another popular approach is to use ordination methods to extract information from NGS 
71 data and describe the variations in community composition among samples (Paliy \&

72 Shankar, 2016). Ordination methods arrange objects in a multidimensional space using

73 directly the original raw data table (e.g., principal component analysis, correspondence

74 analysis), or after computing a distance matrix (e.g., non-metric multidimensional

75 scaling, principal coordinate analysis) (Legendre \& Legendre, 2012).

These different approaches are based on a single table composed of read counts

77 for each Operational Taxonomic Unit (OTU) measured for several samples.

78 Technological advances now make it possible to acquire NGS data on different

79 taxonomic groups simultaneously for the same samples (Fierer et al., 2007) and lead to

80 analyze a pair of tables (i.e., OTUs composition for the same sampling sites for two

81 different taxonomic groups). To analyze such pair of tables, a common practice consists

82 in merging the two tables into a single one and then applying network analysis (e.g.,

83 Kueneman et al., 2016; Banerjee et al., 2016; Ma et al., 2016) and/or multivariate

84 analysis (Cannon et al., 2017; Bergelson, Mittelstrass, \& Horton, 2019). However, this

85 data aggregation is unsuitable especially when NGS data sets, which are a function of

86 sequencing depth (Ni, Yan, \& Yu, 2013), are standardized by dividing read counts by the

87 total number of reads in each sample. In this case, the normalişzation step and further

88 analysis are very sensitive to the difference in number of OTUs and associated counts in

89 each taxonomic group. Hence, it is important to use techniques allowing for the analysis

90 of a pair of NGS data tables while preserving the original structure of the data. In

91 addition, these approaches must be able to mitigate the statistical bias stemming from

92 high-dimensionality (i.e., a number of samples substantially lower than the number of

93 variables), sparsity (i.e., a high proportion of zero counts), and the compositional nature

94 (i.e., a non-independence of relative abundances induced by the row-sum normalisation)

95 that characterize NGS data (Li, 2015). For network analysis, the SPIEC-EASI method has 
96 been adapted to infer associations among microorganisms in a cross-domain analysis

97 (Tipton et al., 2018). For multivariate analyses, several two-table methods exist and

98 have been presented to microbial ecologists in methodological reviews (Ramette, 2007;

99 Buttigieg \& Ramette, 2014; Paliy \& Shankar, 2016). However, these works focused on

100 asymmetric methods (e.g., canonical correspondence analysis_and redundancy analysis)

101 that aim to explain the composition of microbial communities by a limited number of

102 environmental predictors. Unfortunately, these methods are not adapted to link two

103 NGS data tables as they require that there are fewer predictor variables than samples

104 (Dray, Chessel, \& Thioulouse, 2003) and thus are not able to deal with the high-

105 dimensionality of NGS data. Moreover, these methods compute linear combinations of

106 the predictor variables, which is not suitable if the table of predictors contains

107 community data that display unimodal structure and/or are sum normalised (as the NGS 108 data).

109 This study aims to propose an analytical framework based on co-correspondence 110 analysis ( $\mathrm{CoCA}_{2}$ ter Braak \& Schaffers, 2004), a two-table coupling method developed in

111 community ecology, to study the distributions and assemblages between two microbial

112 communities. This framework is based on correspondence analysis, a method that

113 effectively handles proportional data that contain many zeroes (Gauch et al., 1977;

114 Jackson, 1997; Greenacre, 2009), like NGS data (Paulson, Stine, Bravo, \& Pop et al.,

115 2013). We show how this method allows to extract information about the co-structure

116 among two microbial communities to estimate the congruence between them. Finally,

117 we show that the outputs of the method can be used to reorder co-occurrence networks

118 inferred by network analysis to enhance the visualization of microbial association and

119 the understanding of assemblage patterns within networks. Hence, our approach echoes

120 to the current lively debate about the practices to create network visualizations which 
121 are both aesthetically appealing and have high information content (see Pocock et al.,

1222016 for review). We illustrate our approach using two real data sets, one on

123 autotrophic and heterotrophic microbial eukaryotes in shallow freshwater systems and

124 another on microalgae and viruses in marine systems.

125

126 Materials and methods

127 Studying cross-taxon congruence by co-correspondence analysis

128 Co-correspondence analysis (ter Braak \& Schaffers, 2004) is part of the class of

129 canonical analyses with the feature to be designed to analyze a pair of tables containing

130 abundance data and to study the co-variations between two types of communities (e.g.,

131 plants and pollinators). CoCA is based on correspondence analysis (Benzécri, 1969; Hill,

132 1973) and preserves its fundamental properties of weighted averaging and the use of

133 the chi-square $\left(\chi^{2}\right)$ distance for both tables (Supporting Information). The $\chi^{2}$ distance is

134 particularly adapted to NGS data as it handles properly zero values (and in particular

135 double absences) and thus is not hampered by zero inflation (Legendre \& Legendre,

136 2012).

137 Here, co-correspondence analysis in its predictive form ( $\mathrm{pCoCA}$ ) is used for the

138 microalgae-virus data set while the symmetric form ( $\mathrm{soCA}$ ) is used for the microbial

139 eukaryote data set. Let $X=\left[x_{i j}\right]$ and $Y=\left[y_{i k}\right]$ be $n \times p$ and $n \times q$ tables containing the

140 relative abundances of each $p$ and $q$ species of two communities measured at the same $n$

141 samples. In the first case, pCoCA is chosen because we wish to investigate the

142 composition of virus communities under the hypothesis that the occurrence of viruses

143 depends mainly on whether microalgal hosts are present or absent at a particular

144 sample location. In the second case, sCoCA is chosen as we simply wished to study the

145 relationships between autotrophic and heterotrophic microbial eukaryotes. In its 
146 predictive form, CoCA is based on partial least_squares regression analysis (PLS) in a

147 SIMPLS version (ter Braak \& Schaffers, 2004) to deal with high-dimensionality and

148 subsequent collinearity in the table of explanatory variables. PLS searches for a linear

149 regression model from a set of orthogonal components (called latent factors) built from

150 collinear explanatory variables with the constraint that these components maximize the

151 covariance with the response variables (Martens, 2001). In its symmetric form, CoCA fits

152 in the framework of co-inertia analysis (COIA, Dolédec \& Chessel, 1994) that is not

153 affected by the problem of collinearity (Dray, Chessel, \& Thioulouse, 2003). Co-inertia

154 analysis relates two data tables in a symmetric way, by providing a decomposition of the

155 co-inertia criterion on a set of orthogonal axes on which sample scores are projected

156 (Dray, Chessel, \& Thioulouse, 2003).

157 In practice, CoCA identifies associations (or common ecological gradients)

158 between two types of biological assemblages from the same samples, by seeking the

159 factorial axes that maximize the covariance between the weighted average sample

160 scores (projection of rows of one table onto the factorial axes) of one community with

161 those of the other community (Supporting Information, Eq. 12). This requires to

162 determine species scores (projection of columns of one table onto the factorial axes) of

163 one table as weighted averages of sample scores of the other table and sample scores as

164 weighted averages of the species scores of their own table (Supporting Information, Eq.

$165 \underline{13-16)}$. So, pCoCA and sCoCA are a weighted version of PLS and COIA, respectively.

166 Given that CoCA is related to the correspondence analysis, it is necessary to circumvent

167 the fact that the sample weights of $\mathrm{Y}$ and $\mathrm{X}\left(R_{1}\right.$ and $R_{2}$, which are the row sums of $\mathrm{Y}$ and

$168 \underline{\mathbf{X}}$, respectively) are imposed and are not similar (Supporting Information, Eq. 6 and Eq.

169 7). This does not meet a crucial constraint in estimating the co-structure between two

170 tables, namely that the samples must be weighted in the same way for the two tables 
(Dray, Chessel \& Thioulouse, 2003). Hence, an additional common sample weights matrix $\left(R_{0}\right)$ is defined to replace $R_{1}$ and $R_{2}$ so that the weighted averaging properties of CA can be retained in CoCA (ter Braak \& Schaffers, 2004). In pCoCA, $R_{0}$ is equal to the sample weights of the community response table (i.e., $R_{0}=R_{1}$ ), whereas in sCoCA, $R_{0}=\left(R_{1}+R_{2}\right) / 2$ (Supporting Information, Eq. 10 and Eq. 11). Note that in the specific case of compositional data, the row sums are equal to 1 and $R_{0}=R_{1}=R_{2}$.

\section{Ordination of the structure and assemblage of interacting communities} From sCoCA, ordination diagrams can be made in the usual way by jointly plotting the species scores and sample scores (of each community) for the first axes of the analysis (ter Braak \& Schaffers, 2004). For an optimal representation of this association in a biplot, the species scores of each axis must be multiplied by the quarter root of the eigenvalue of the axis (ter Braak, 1990). From pCoCA, the fit of the response community (viruses) to the predictive community (microalgal hosts) as well as the variations in the composition of communities can be displayed in ordination diagrams (biplots; ter Braak \& Schaffers, 2004). For instance, the joint plot of sample scores of hosts (table $\mathbf{X}$ ) with species scores of viruses (table $\mathbf{Y}$ ) displays the fit of the virus OTUs from the host communities. The simultaneous plot of sample scores of microalgae with the loadings $\underline{\text { (i.e., the coefficient or importance of variables on the first components of }}$ the PLS) of predictor species (i.e., hosts) allows representing microalgae communities and their OTUs. Both types of OTUs can also be jointly displayed using scores of the response species (i.e., viruses) with the loadings of predictor species (i.e., microalgae).

For all these diagrams, axes are optimized to maximize covariance between assemblages rather than to depict associations within individual species matrices, but interpretation 
195 can also be carried out as in correspondence analysis according to the barycentre

196 principle, where OTUs are placed at the barycentre (weighted average) of the sample

197 points and, by symmetry, samples at the barycentre (weighted average) of the OTUs

198 (Supporting Information, Eq. 13-16).

200 Real data application

201 We illustrate the use of CoCA to study the congruence between microbial

202 communities from NGS data, employing data of Simon et al. (2015) on the study of

203 autecology of microbial eukaryotes in shallow freshwater systems, and a data set

204 acquired during our research program (ANR program DECOVIR-12-BSV7-0009) on the

205 monitoring of microalgae and viruses in marine systems.

206

207 Case study 1: Microbial eukaryotes

208 Surface water was sampled monthly from April 2011 to April 2013 in five small

209 shallow freshwater systems [four ponds: Etang des Vallées (EV), La Claye (LC), Mare

210 Gabard (GB), Saint Robert (SR), and one brook: Ru Sainte Anne (RSA)], located at the

211 Natural Regional Park of the Chevreuse Valley (South of Paris, France). These systems

212 were characterized by different local environmental conditions. Briefly, raw genomic

213 sequences were obtained from 18S rDNA fragments, encompassing the V4

214 hypervariable region, applying 454 pyrosequencing and filtered to remove potential

215 spurious sequences using a local pipeline (Simon et al., 2014). Sequences from all

216 samples were then processed together and clustered into OTUs at 0.98 similarity cutoff

217 using $\mathrm{CD}$ hit ( $\mathrm{Fu}, \mathrm{Niu}, \mathrm{Zhu}, \mathrm{Wu}, \mathcal{E} \mathrm{Li}, 2012$ ), and singletons were eliminated, before to

218 assign OTUs to taxonomic groups based on sequence similarity to the PR2 database

219 (Guillou et al., 2013). From this overall OTU table, we used the method applied by Simon 
220 et al. (2015) to select the most abundant OTUs. Finally, we subdivided the data set by

221 grouping OTUs in two functional groups (autotrophic and heterotrophic) trained on

222 literature information (Simon et al., 2015; Genitsaris, Monchy, Breton, Lecuyer, \&

223 Christaki, 2016 and references within), and we obtained one table for autotrophic

224 microbial eukaryotes $(n=108, p=122)$ and another table for microbial heterotrophic

225 eukaryotes $(n=108, q=104)$.

226

227 | Case study 2: Microalgae-virus system

228 The data set coming from our research program contains a NGS-based eukaryotic

229 microalgae community table (photosynthetic picoeukaryotes in the class

230 Mamiellophyceae) and a NGS-based virus community table (viruses infecting this class

231 of eukaryotic phytoplankton and belonging to the genera Prasinovirus of the family

232 Phycodnaviridae). The data have been acquired across four sites located in northwest

233 Mediterranean Sea (Gulf of Lion) and sampled monthly from March 2013 to April 2014.

234 The Gulf of Lion is characterized by contrasted environments, including eutrophic

235 lagoons connected to the sea, nutrient-rich coastal sites, and oligotrophic open-sea

236 locations. The sample locations included two sites in Leucate lagoon (one coastal site

237 (LB) and another site (LA) at the level of the Grau, i.e. the connection with the sea), a

238 coastal site (SA, marine station included in the French marine monitoring network

239 SOMLIT) and an open-sea site (MA, marine station included in the monitoring network

240 MOOSE). The characterization of Prasinovirus was based on analyzing the partial

241 sequence of the DNA polymerase gene (PolB) amplified using two primer sets (Chen $\mathcal{E}$

242 Suttle, 1995; Clerissi et al., 2014). For Mamiellophyceae, the sequence of the V9 region of

243 the 18S rDNA was amplified using primers defined by Amaral-Zettler, McCliment,

244 Ducklow, \& Huse (2009). The genomic sequences of PolB and V9 region were amplified 
245 and sequenced using an Illumina MiSeq platform (GeT-PlaGe, INRA, Castanet-Tolosan,

246 France). Sequences were processed and clustered into OTUs at 0.99 similarity cutoff and

247 singletons were removed using MOTHUR v 1.35.1 (Schloss et al., 2009) for

248 Mamiellophyceae and USEARCH v7 (Edgar, 2010) combined with MUSCLE software

249 (Edgar, 2004) for Prasinovirus. Sequences were then compared against the PR2 database

250 (Guillou et al., 2013) and the NCBI database for Mamiellophyceae and Prasinovirus,

251 respectively, in order to assign OTUs to taxonomic groups based on similarity. Finally,

252 we focused specifically on OTUs assigned to the family Mamiellales of the class

253 Mamiellophyceae, and notably the genus Bathycoccus, Micromonas and Ostreococcus

254 which usually dominate this class in the Gulf of Lion and more generally the

255 picoeukaryotic fraction in other ecosystems (Wu, Huang, \& Zhong, 2013; Zhu, Massana,

256 Not, Marie, \& Vaulot, 2005). Subsequently, the Prasinovirus data set was limited to OTUs

257 assigned as Bathycoccus viruses (BpVs), Micromonas viruses (MpVs) and Ostreococcus

258 viruses (OtVs). The dominant microalgae and virus OTUs (i.e., $\geq 0.1 \%$ of mean relative

259 abundance for at least two samples) were selected to obtained one microalgae table (

$260 n=31, p=67)$ and one virus table $(n=31, q=98)$.

\section{Statistical analysis}

263 Tables $\mathbf{X}$ and $\mathbf{Y}$ of autotrophic and heterotrophic microbial eukaryotes, respectively, were subjected to $\mathrm{sCoCA}$. To test the significance of the global co-variation between the two tables a $_{\text {a }}$ Monte-Carlo permutation procedure with 9999 permutations was used. In each permutation, sCoCA (by considering all axes) is reapplied to obtain a

267 value of the co-variance between table $\mathrm{Y}$ and row-permuted $\mathrm{X}$ (so that samples are

268 randomized while preserving the relative abundance of individuals). Note that the

269 choice of the table to be reordered is not important here since we used the symmetric 
270 form of the CoCA. A null distribution was estimated from co-variance calculated for the

271 permuted data. The observed co-variance is then compared to the distribution obtained

272 under the null hypothesis. The positions of the samples on ordination axis of each table

273 are then correlated to show the overall level of co-variation between them. For the

274 microalgae-virus data set, both tables were subjected to pCoCA with the SIMPLS

275 algorithm. ter Braak \& Schaffers (2004) suggest that the number of axes used to

276 summarize the data can be selected by "leave-one-out" cross-validation procedure to

277 maximize the cross-validatory fit (\%) that measures how well the table $\mathbf{X}$ (microalgae in

278 our case) predicts the response table $\mathbf{Y}$ (viruses in our case). Working just with these

279 significant axes provides a measure of association between the tables by removing

280 random noise and keeping only the major dimensions of ecological variability. Finally,

281 we combine CoCA and network analysis so that nodes in co-occurrence networks are

282 reordered according to the species scores from the CoCA, and thus from the co-structure

283 between communities. A novel extension of SPIEC-EASI (Tipton et al. 2018) was used to

284 infer the cross-group co-occurrence networks between two data sets. We used the

285 neighborhood (MB) setting and selected the optimal sparsity parameter based on the

286 Stability Approach to Regularization Selection (StARS) (Liu, Roeder, \& Wasserman,

287 2010). The StARS variability threshold was set to 0.05 for networks built from the two

288 data sets. All statistical analyses were performed with the R software (R Core Team,

289 2019) and using the cocorresp package (Simpson, 2009) for CoCAs and the SpiecEasi

290 package (Kurtz et al., 2015) for co-occurrence networks. Appendix 1 contains a $R$ script

291 and example data (from the case study 1 and the case study 2) allowing users to

292 reproduce the analysis and apply them on their own data sets.

\section{Results}


sCoCA axis 2: $10.55 \%$, sCoCA axis 3: $10.01 \%$ ). The first three ordination axes of the

autotrophic eukaryotes were highly correlated with the first three ordination axes of the

302 heterotrophic eukaryotes (correlations being $0.95,0.92$, and 0.92 ), demonstrating a high

303 degree of similarity in change between autotrophic and heterotrophic microbial

304 eukaryote assemblages. Communities of autotrophic and heterotrophic microbial

305 eukaryotes covaried along a brook/pond gradient on the first axis (from left to right),

306 and an inter-pond variability on the second axis (Figure 1). Marked differences in the

307 composition of the two communities are visible in joint plots. In the brook system (i.e.,

308 RSA), the heterotrophic microbial eukaryote community is mainly composed of fungi,

309 MAST, Labyrinthulida, and Telonema, whereas in pond systems (i.e., EV, LC, MG, SR)

310 Ciliophora, Biocosoecida, Katablepharida, and Choanoflagellida dominated the

311 communities (Figure 1a). Differences between pond systems are explained with higher

312 relative abundance of Biocosoecida, and Katablepharida in EVs and LCs and higher

313 relative abundance of Ciliophera in SRs. Species scores of autotrophic microbial

314 eukaryotes indicated that the patterns in heterotrophic communities are associated to a

315 structure of the autotrophic community (Figure 1b). In the brook system, the

316 autotrophic microbial eukaryote community exhibits high relative abundances of

317 specific OTUs of Bacillariophyceae, Chrysophyte and Cryptophyta. In pond systems,

318 autotrophic communities made up mainly of other specific OTUs of Chlorophyta, 
319 Chrysophyte, and Cryptophyta. It is also worth noting that Dinophyta and Streptophyta

320 were found exclusively in pond systems (in particular in MG and SR, respectively).

321 The community organization of microbial eukaryotes was highlighted from a

322 cross-group co-occurrence network between autotrophic and heterotrophic individuals.

323 Among 226 dominant autotrophic and heterotrophic OTUs, 204 displayed 274

324 associations (Figure 2). From these associations between OTUs in the network, more

325 positive (98.5\%) than negative associations were inferred. All negative associations

326 occurred between OTUs assigned to Ciliphora for heterotrophic microorganisms and

327 Cryptophyta for autotrophic microorganisms. No clear association patterns can be

328 identified in network from raw tables of autotrophic and heterotrophic microbial eukaryotes (Figure $2 \mathrm{a}$ ). When the co-occurrence network is reordered according to

330 species scores on the first axis of sCoCA, two modules can be distinguished (Figure $\underline{2} b$ ).

331 The first module (i.e., top right corner) is constituted by OTUs exhibiting the higher

332 relative abundances in brook system (i.e., RSA), while OTUs that compose the second

333 module (i.e., bottom left corner) dominate pond systems (i.e., EV, LC, MG, and SR).

334 Heterotrophic OTUs exhibited major associations with autotrophic OTUs belonging to

335 the same module, with only $1.5 \%$ of associations between OTUs from distinct module. A

336 striking pattern is that Chrysophyte is the autotrophic group that contributes most to

337 associations in the two modules (module 1: 71\%, module 2: $41 \%$ ), whereas for the

338 heterotrophic group it is fungi in the module $1(47 \%)$ and Ciliophora in the module 2

339 (59\%). In pond systems (i.e., module 2), surprisingly, fungi are involved in very few

340 associations (7\%). 
344 first two significant axes (pCoCA axis 1: $p=0.001$, pCoCA axis 2: $p=0.001$ ), in which

345 Mamiellophyceae community predicted $32.02 \%$ of the variation in Prasinovirus

346 community. The first two axes accounted for $37.47 \%$ ( $24.26 \%$ and $13.21 \%$ for axis 1 and

3472 respectively) and $44.82 \%(28.01 \%$ and $16.81 \%)$ of the variation in the structure of

348 Mamiellophyceae and Prasinovirus community respectively. The biplots indicated that

349 the two communities covaried along a lagoon (samples LAs)/open-sea gradient

350 (samples MAs) on the first axis (from left to right), while a temporal gradient for site LA

351 (intra-site variability) could be identified along the second axis (Figure $\underline{3}$ ). OtVs have a

352 higher prevalence in the lagoon samples (especially LAs) and coastal samples (SAs) in

353 which Ostreococcus exhibited a high density (Figure $\underline{3} \mathrm{a}, \mathrm{b}$ ). Conversely, open-sea

354 samples (MAs) were dominated by Bathycoccus which supported virus assemblages

355 dominated by BpVs. Micromonas showed a wider distribution, with a relative

356 contribution of its OTUs both in lagoon samples, coastal samples and open-sea samples,

357 associated with a similar repartition of MpVs (Figure $\underline{3} \mathrm{a}, \mathrm{b}$ ).

358 Based on the cross-group co-occurrence networks analysis, 67 associations were

359 identified between the major 67 OTUs assigned to one of the three groups of

360 Mamiellophyceae (i.e. Bathycoccus, Micromonas, and Ostreococcus) and the major 98

361 OTUs assigned to Prasinovirus (i.e. BpVs, MpVs, and OtVs) (Figure 4a). Reordering the

362 co-occurrence network according to the species scores on the first axis of pCoCA

363 highlighted a structure in the network (Figure 4b). The network topology suggests that

364 the identity of OTUs contained in co-occurring groups of viruses and microalgae are

365 related to their respective prevalence along the lagoon/open-sea gradient. Virus OTUs

366 mostly present in lagoon samples have significant associations primarily with

367 microalgae OTUs displaying the higher prevalence in lagoon samples (top right corner, 
368 Figure 4b). Similarly, virus OTUs dominating the open-sea samples were mainly

369 associated with microalgae OTUs from open-sea samples (bottom left corner, Figure 4b).

370 Among the associations contained in the network, 50 were identified between OTUs

371 belonging to an expected host-virus system (i.e. associations Bathycoccus/BpV,

372 Micromonas $/ \mathrm{MpV}$, and Ostreococcus $/ \mathrm{OtV}$ ) while the other 17 significant associations

373 were found between OTUs belonging to different host-virus systems. In average 50\%,

$37470.6 \%$ and $91.3 \%$ of associations found for OTUs of BpVs, MpVs, and OtVs respectively

375 were with OTUs assigned to their respective host group. Within the associations, some

376 single Mamiellophyceae OTUs were associated with many Prasinovirus OTUs and

377 reciprocally. On the other hand, dyads were identified, that is specific associations, in

378 Bathycoccus/BpV, Micromonas/MpV and Ostreococcus/OtV systems. Few negative

379 associations inferred from the observation that those OTUs do not co-occur were found

380 in network (Figure 4b). Interestingly, eight negative associations from a total of nine

381 involved virus OTUs and microalgae OTUs belonging to different host-virus systems.

\section{Discussion}

384 Critical review and guidance papers on the analysis of NGS-based community 385 data (Ramette, 2007; Buttigieg \& Ramette, 2014; Paliy \& Shankar, 2016) do not mention 386 any direct quantitative method for predicting the composition of one community from 387 another. Co-correspondence analysis (ter Braak \& Schaffers, 2004) fills this gap. At the 388 level of the case study 1 , symmetric form of CoCA indicated that heterotrophic microbial 389 eukaryote assemblages in shallow freshwater ecosystems were strongly associated with 390 patterns of autotrophic microbial eukaryotes presence and abundance with links that 391 can be taxon-specific (Figure 1). Our results shown also that the composition of 392 heterotrophic microbial eukaryote community was dominated by fungi in brook system 
compared to ponds. This is in line with recent observations, based on the estimation of ergosterol level, of a generally higher fungal biomass in river than in ponds (Baldy et al., 2002). Higher fungal abundance might potentially be linked to incoming resources from runoff, since in brooks the most important source of imported material is usually deciduous leaves, whose the decomposition processing involved to a large extent fungi (Bärlocher, 1985; Webster \& Benfield, 1986). To this the composition of heterotrophic microbial eukaryote community characterizing brook system is associated a specific composition of microbial autotrophs. Such a result suggests that heterotroph community composition exert a control on the composition of autotroph community,

402 and that microbial autotrophs can be driver of microbial heterotrophs.

distribution patterns among the three groups of Prasinovirus along the lagoon/open-sea gradient (Figure $\underline{3}$ ). Note the importance of the dimension reduction step in pCoCA that

407 removes random variation from the data. The patterns in Prasinovirus assemblages, with

408 a dominance of $\mathrm{OtV}$ in lagoon and coastal samples compared to offshore locations, the

409 inverse distribution for $\mathrm{BpV}$, and $\mathrm{MpV}$ exhibiting a wider spatial distribution, are in part

410 a consequence of the presence of their respective hosts in lagoon, coastal and open-sea

411 samples. Indeed, Ostreococcus is known to be abundant in lagoons (Subirana et al.,

412 2013), more eutrophic system, compared to Bathycoccus, which is found mainly in

413 oligotrophic areas (Vaulot et al., 2012; Wu, Huang, \& Zhong, 2013) such as offshore sites

414 (i.e., MA). Micromonas is ubiquitous and particularly present in nutrient-rich

415 environments (Not et al., 2004; Viprey, Guillou, Ferréol, \& Vaulot, 2008). Our findings

416 confirm also the data of Bellec et al. (2010) showing that OtV are more abundant in

417 lagoon than in the open sea. 
419 Paasivirta, \& Muotka, 2009; Gioria, Bacaro, \& Feehan, 2011) provides a more

420 comprehensive picture of the community similarity than the richness metrics

421 conventionally used (Wolters, Bengtsson, \& Zaitsev, 2006; Westgate, Barton, Lane, \&

422 Lindenmayer, 2014). Our results reinforce the need to use CoCA to study the cross-taxon

423 congruence in microbial communities from NGS data. This is all the more important

424 because the high co-correspondence between the two functional groups in microbial

425 eukaryote community may be especially informative given the key ecological role of

426 microbial eukaryotes (Caron et al., 2012). In addition, the study of cross-taxon

427 congruence between Mamiellophyceae and Prasinovirus is of definite interest in marine

428 ecosystems, warmed by climate change, where the expected gradual shift towards small

429 primary producers could render the role of small eukaryotes more important than they

430 are today (Morán, López-Urrutia, Calvo-Díaz, \& Li, 2010). Microbial eukaryotes are

431 recognized as a significant contributor across various geographical locations of

432 picophytoplankton (Worden, Nolan, \&Palenik, 2004; Jardillier, Zubkov, Pearman, \&

433 Scanlan, 2010), which accounts for $>50 \%$ of phytoplankton biomass and productivity in

434 marine ecosystems (Maranon et al., 2001; Teira et al., 2005).

435 Previous studies have suggested that biotic interactions are the most likely

436 mechanisms underlying cross-taxon congruence at local scales (Jackson \& Harvey, 1993;

437 Johnson \& Hering, 2010), although concordance is also expected from similar responses

438 to environmental gradient (Bini, Vieira, Machado, \& Machado Velho et al., 2007; Rooney

439 \& Bayley, 2012). As an important implication, the level of congruence can inform about

440 the structural pattern among interacting groups (Özkan et al., 2014). That being said,

441 reordering co-occurrence networks, from the species scores on the first axis of CoCA,

442 allows to identify structural patterns in co-occurrence networks of microbial eukaryote 
443 community (Figure $\underline{2 b}$ ) and in the Mamiellophyceae/Prasinovirus system (Figure 4b).

444 For example, the structure of the microbial eukaryote network is characterized by two

445 modules underlying a brook/pond gradient in the composition of heterotrophic and

446 autotrophic microbial eukaryote assemblages. These differences in OTU composition

447 within the two modules suggest that the food-web structure is different between lotic

448 and lentic ecosystems, and reinforce the differences previously observed at the

449 bacterioplankton level (Portillo, Anderson, \& Noah, 2012). A substantial effort has been

450 made in the development of metrics to estimate and test the level of nestedness (e.g.,

451 Rodriguez-Guirones \& Santamaria, 2006; Ulrich \& Gotelli, 2007) and modularity (e.g.,

452 Barber, 2007; Dorman \& Strauss, 2014) within interaction networks. The order of

453 individuals of two groups in bipartite matrices affects the magnitude of metrics that

454 represent deviations from an idealized state (e.g., perfect nestedness or modularity)

455 (Almeida et al., 2008). It has then been advocated that prior to analysis of structure of

456 networks, original bipartite matrices should be reordered to maximize the coherence of

457 individual distributions in rows and columns, so that individuals with most similar links

458 are close together (Borgatti \& Everett, 1997; Leibold \& Mikkelson, 2002). These findings

459 taken together with our results validate our proposition to combine CoCA with network

460 analysis to study structural patterns of microbial networks. In addition, in reverse to the

461 expected view of nestedness structure of phage-bacteria network (Flores, Meyer,

462 Valverde, Farr, \& Weitz, 2011), the modular structure of Mamiellophyceae/Prasinovirus

463 network observed in the field underpinned the modularity patterns previously observed

464 in phage-bacteria network from cross-infection experiments (Flores, Valverde, $\mathcal{E}$ Weitz,

465 2013). Given that the structure of interaction networks is constraint by the

466 coevolutionary processes between species (Peralta, 2016), this would lead to account

467 for phylogenetic signals within co-occurrence network (Derocles et al., 2018). In this 
context, it would be possible to disentangle the confounding effect of phylogeny from

true biotic interactions by developing a partial analysis (ter Braak, Šmillauer \& Dray,

2018) in the context of CoCA to partial out the phylogenetic effect and focus on patterns

471 of co-occurrence that are not related to phylogenetic signal.

All computational methods used to infer networks from NGS data sets produce species co-occurrence networks, where a link between two species represents a

474 significant statistical association (positive or negative) between their abundance. This

475 raises a critical issue about the interpretation of inferred associations (Derocles et al.,

476 2018), because co-occurrence networks differ from interaction networks constructed on

477 observations of both the species and their interactions (Ings et al., 2009). For instance,

478 all inferred associations between Mamiellophyceae and Prasinovirus belonging to

479 expected host-virus system were positive. These results are consistent with a previous

480 work showing that when parasitism is captured as a significant link in co-occurrence

481 network, it is retrieved as a positive link despite the detrimental effect of parasite on its

482 host (Weiss et al., 2016). This might be explained because the copresence of the host

483 species and the parasite species is necessary for the interaction to occur. Another

484 surprising result is that all negative associations (expected one) were between

485 Mamiellophyceae and Prasinovirus belonging to different host-virus systems. Such

486 negative associations may account for opposite abiotic requirements, since in our case,

487 OTUs of concerned viruses and microalgae had inverse spatio-temporal dynamics.

488 Positive associations were also found between individuals of different host-virus

489 systems, which could be explained by the increase of a Prasinovirus population that

490 removes, by infection, a major competitor of a co-occurring Mamiellophyceae host of

491 another group. It is important to keep in mind that, although these associations between

492 microalgae and Prasinovirus suggest that they interact, they do not necessarily mean 
493 that the co-occurring Mamiellophyceae are the virus hosts, even if they belong to the expected group of hosts (e.g., Bathycoccus, Micromonas or Ostreococcus). Our approach (CoCA combined with network analysis, or other method to infer associations ) could be combined with other approaches, e.g. single cell genomics (Kalisky, Baliney, \& Quake, 2011; Martinez-Garcia et al., 2012), Epic-PCR (Spencer et al., 2016), to validate the predicted associations in interactions. The justification of the association sign between the two functional groups making up the microbial eukaryote community is also not straightforward, although they can be triggered by ecological interactions or by species

501 abiotic requirements (Derocles et al., 2018). In conclusion, the successful application of co-correspondence analysis over two real data sets of microbial communities exhibiting various types of interactions

504 reinforces that resorting to this method for study the distributions, assemblages and 505 interactions between two microbial communities constitutes a highly valuable approach

506 to understand the cross-taxon congruence between microorganisms. A useful

507 consequence of cross-taxon congruence is that the distribution of well-known taxa may

508 provide insight into the processes structuring the distribution of other taxa (e.g., Bilton,

509 McAbendorth, Bedford, \& Ramsay, 2006; Santi et al., 2010). This approach could be used

510 to enhance our understanding of a major problem, the effect of phytoplankton bloom (in

511 particular toxic groups such as cyanobacteria) on the microbial communities and in turn

512 on the ecosystem functions (e.g., Yang et al., 2016; Xue et al., 2018). Our findings also

513 demonstrate that the reordering of co-occurrence networks, according to the

514 congruence information extracted from CoCA, allows to investigate the presence of

515 ecological signals in networks. The advantage of this approach is that the complexity of

516 the network is considerably reduced by the non-random placement of nodes in the

517 space in such a way as to improve the aesthetic quality of the representation and 
518 consequently its readability, as proposed in good practice of data visualization

519 (Spiegelhalter, Pearson, \& Short, 2011; Kjærgaard, 2015; Pocock et al., 2016).

520 Interestingly, the applicability of our approach goes beyond the particular case of data

521 sets with row-sum normalisation (i.e., compositional data). Indeed, CoCA was originally

522 designed to analyze abundance data and is thus able to deal with counts without the

523 need to rarefy data, in accordance with the recent advice against rarefaction (McMurdie

$524 \&$ Holmes, 2014). It paves the way for further studies to examine the cross-taxon

525 congruence and structural pattern of co-occurrence networks in microbial communities

526 and in turn their effects on the ecosystem functioning.

527

528 Acknowledgments

529 We are grateful for financial support from the French National Research Agency

530 (DECOVIR ANR-12-BSV7-0009, coordinator Y.D.). We thank Ludwig Jardillier for give us

531 access to genomic data on autotrophic and heterotrophic microbial eukaryotes. 
533

534

535

536

537

538

539

540

541

542

543

544

545

546

547

548

549

550

551

552

553

554

555

556

557

558

559

560

561

562

563

564

565

566

567

568

569

570

571

572

573

574

575

576

577

578

579

Almeida-Neto M, Guimarães P., Guimarães P. R. Jr., Loyola R. D., \& Ulrich W. (2008). A consistent metric for nestedness analysis in ecological systems: reconciling concept and measurement. Oikos, 117, 1127-1239.

Amaral-Zettler, L. A., McCliment E. A., Ducklow H. W., \& Huse S.M. (2009). A method for studying protistan diversity using massively parallel sequencing of V9 hypervariable regions of small-subunit ribosomal RNA genes. PLoS One, 4, e6372.

Baldy V., Chauvet E., Charcosset J.-Y., \& Gessner M. O. (2002). Microbial dynamics associated with leaves decomposing in the mainstem and floodplain pond of a large river. Aquatic Microbial Ecology, 28, 25-36.

Bálint M., Bahram M., Eren A. M., Faust K., Fuhrman J. A., Lindahl B., ... Tedersoo L. (2016). Millions of reads, thousands of taxa: microbial community structure and associations analyzed via marker genes. FEMS Microbial Reviews 40, 686-700.

Ban Y, An L., \& Jiang H. (2015). Investigating microbial co-occurrence patterns based on metagenomics compositional data. Bioinformatics, 31, 3322-3329.

Banerjee S., Kirkby C. A., Schmutter D., Bissett A., Kirkegaard J. A., \& Richardson A. E. (2016). Netowrk analysis reveals functional redundancy and keystone taxa amongst

Barber M. J. (2007). Modularity and community detection in bipartite networks. Physical Review, 76, 066102.

Bärlocher F. (1985). The role of fungi in the nutrition of stream invertebrates. Botanical Journal of the Linnean Society, 91, 83-94.

Bellec L., Grimsley N., Derelle E., Moreau H., \& Desdevises Y. (2010). Abundance, spatial distribution and genetic diversity of Ostreococcus tauri viruses in two different environments. Environmental Microbiology Reports, 2, 313-321.

Benzécri F. (1969). Statistical analysis as a tool to make patterns emerge from data. In Watanabe (Ed.), Methodologies of pattern recognition. (pp 35-60). Academic Press: New York.

Bergelson J., Mittelstrass J., \& Horton M. W. (2019). Characterizing both bacteria and fungi improves understanding of the Arabidopsis root microbiome. Scientific Reports, 9, 24 .

Bilton D. T., McAbendorth L., Bedford A., \& Ramsay P. M. (2006). How wide to cast the net? Cross-taxon congruence of species richness, community similarity and indicator taxa ponds. Freshwater Biology, 51, 578-590.

Bini L. M., Vieira L. C. G., Machado J., \& Machado Velho L. F., (2007). Concordance of species patterns among micro-crustaceans, rotifers and testate amoebae in a shallow pond. International Review of Hydrobiology, 92, 9-22.

Borgatti S. P., \& Everett M. G. (1997). Network analysis of 2-mode data. Social Networks, $19,243-269$.

Buttigieg P. L., \& Ramette A. (2014). A guide to statistical analysis in microbial ecology: a community-focused, living review of multivariate data analyses. FEMS Microbiology Ecology, 90, 543-550.

Cannon M. V., Craine J., Hester J., Shalkhauser A., Chan E. R., Logue K., ... Serre D. (2017). Dynamic microbial populations along the Cuyahoga River. PLoS ONE, 12, e0186290.

Cardona C., Weisenhorn P., Henry C., \& Gilbert J. A. (2016). Network-based metabolic analysis and microbial community modeling. Current Opinion in Microbiology, 31 , 124-131.

Caron D. A., Countway P. D., Jones A. C., Kim D. Y., \& Schnetzer A. (2012). Marine protistan diversity. Annual Review of Marine Science, 4, 467-493. 
Chen F., \& Suttle C. A. (1995). Amplification of DNA polymerase gene fragments from viruses infecting microalgae. Applied and Environmental Microbiology, 61, 12741278.

Clerissi C., Grimsley N., Ogata H., Hingamp P., Poulain J., \& Desdevises Y. (2014). Unveiling of the diversity of Prasinoviruses (Phycodnaviridae) in marine samples by using high-throughput sequencing analyses of PCR-amplified DNA polymerase and major capsid protein genes. Applied and Environmental Microbiology, 80, 3150-3160.

Cordero O. X., \& Datta M. (2016). Microbial interactions and community assembly at microscales. Current Opinion in Microbiology, 31, 227-234.

Derocles S. A. P., Bohan D. A., Dumbrell A. J., Kitson J. J. N., Massol, F., Pauvert C., ... Evans D. M. (2018) Biomonitroing for the $21^{\text {st }}$ century: Integrating next-generation sequencing into ecological network analysis. Advances in Ecological Research, 58, 362.

Dolédec S., \& Chessel D. (1994). Co-inertia analysis: an alternative method for studying species-environment relationships. Freshwater Biology, 31, 277-294.

Dormann C. F., \& Strauss R. (2014). A method for detecting modules in quantitative bipartite networks. Methods in Ecology and Evolution, 5, 90-98.

Dray S., Chessel D., \& Thioulouse J. (2003). Co-inertia analysis and the linking of ecological data tables. Ecology, 84, 3078-3089.

Ducklow H. (2008). Microbial services: Challenges for microbial ecologists in a changing world. Aquatic Microbial Ecology, 53, 13-19.

Edgar R. C. (2004). MUSCLE: multiple sequence alignment with high accuracy and high throughput. Nucleic Acids Research, 32, 1792-1797.

Edgar R. C. (2010). Search and clustering orders of magnitude faster than BLAST. Bioinformatics, 26, 2460-2461.

Falkowski P. G., Fenchel T., \& Delong E. F. (2008). The microbial engines that drive earth's biogeochemical cycles. Science, 320, 1034-1038.

Fang H., Huang C., Zhao H., \& Deng M. (2015). CCLasso: correlation inference for compositional data through Lasso. Bioinformatics, 31, 3172-3180.

Faust K., Sathirapongsasuti J. F., Izard J., Segata N., Gevers D., Raes J., \& Huttenhower C. (2012). Microbial co-occurrence relationships in the human microbiome. PloS Computational Biology, 8, e1002602.

Fierer N., Breitbart M., Nulton J., Salamon P., Lozupone C., Jones R., ... Jackson R. B. (2007) Metagenomic and Small-Subunit rRNA analyses reveal the genetic diversity of bacteria, archaea, fungi, and viruses in soil. Applied and Environmental Microbiology, 73, 7059-7066.

Flores C. O., Meyer J. R., Valverde S., Farr L., \& Weitz J. S. (2011). Statistical structure of host-phage interactions. Proceedings of the National Academy of Sciences of the United States of America, 108, E288-E297.

Flores C. O., Valverde S., \& Weitz J. S. (2013). Multi-scale structure and geographic drivers of cross-infection within marine bacteria and phages. ISME Journal, 7, 520532.

Friedman J., \& Alm E. J. (2012). Inferring correlation networks from genomic survey data. PloS Computational Biology, 8, e1002687.

Fu L., Niu B., Zhu Z., Wu S., Li W. (2012). CD-HIT: accelerated for clustering the nextgeneration sequencing data. Bioinformatics, 28, 3150-3152.

Fuhrman J. A. (2009). Microbial community structure and its functional implications. Nature, 459, 193-199. 
Gauch H. G. Jr., Whittaker R. H., \& Wentworth T. R. (1977). A comparative study of reciprocal averaging and other ordination techniques. Journal of Ecology, 65, 157174.

Genitsaris S., Monchy S., Breton E., Lecuyer E., \& Christaki U. (2016). Small-scale variability of protistan planktonic communities relative to environmental pressures and biotic interactions at two adjacent coastal stations. Marine Ecology Progress Series, 548, 61-75.

Gioria M., Bacaro G., \& Feehan J. (2011). Evaluation an interpretating vorss-taxon congruence: Potential pitfalls and solutions. Acta Oecologia, 37, 187-194.

Graham E. B., Knelman J. E., Schindlbacher A., Siciliano S., Breulmann M., Yannareli A., ... Nemergut D. R. (2016). Microbes as engines of ecosystem function: When does community structure enhance predictions of ecosystem processes? Frontiers in Microbiolgy, 7, 214.

Greenacre, M. (2009). Power transformation in correspondence analysis. Computational Statistics \& Data Analysis, 53, 3107-3116.

Guillou L., Bachar D., Audic S., Bass D., Berney C., Bittner L., ... Christen R. The protest Ribosomal Reference database (PR2): a catalog of unicellular eukaryote small subunit rRNA sequences with curated taxonomy. Nucleic Acids Research, 41, D597-D604.

Handelsman J. (2004). Metagenomics: Application of genomics to uncultured microorganisms. Microbiology and Molecular Biology Reviews, 68, 669-685.

Hill M. O. (1973). Reciprocal averaging: an eigenvector method ordination. Journal of Ecology, 61, 237-249.

Hutchins D. A., \& Fu F. (2017). Microorganisms and ocean global change. Nature Microbiology, 2, 17058.

Ings T. C., Montoya J. M., Bascompte J., Blüthgen N., Brown L. Dormann C. F., ... Woodward G. (2009). Ecological network - beyond food webs. Journal of Animal Ecology, 78, 253-269.

Jackson D. A. (1997). Compositional data in community ecology: the paradigm or peril of proportions? Ecology, 78, 929-940.

Jackson D. A., \& Harvey H. H. (1993). Fish and benthic invertebrates: community concordance and community-environment relationships. Canadian Journal of Fisheries and Aquatic Sciences, 50, 2641-2651.

Jardillier L., Zubkov M. V., Pearman J., \& Scanlan D. J. (2010). Significant $\mathrm{CO}_{2}$ fixation by small prymnesiophytes in the subtropical and tropical northeast Atlantic Ocean. ISME Journal, 4, 1180-1192.

Johnson R. K., \& Hering D. (2010). Spatial congruency of benthic diatom, invertebrate, macrophyte, and fish assemblages in European streams. Ecological Applications, 20, 978-992.

Kalisky T., Baliney P., \& Quake S. R. (2011). Genomics analysis et the single-cell level. Annual Review of Genetics, 45, 431-445.

Kjærgaard R. S.. (2015). Data visualization: mapping the topical space. Nature, 520, 292293.

Kueneman J. G., Woodhams D. C., Treuren W. V., Archer H. M., Kniht R., \& McKenzie V. J. (2016). Inhibitory bacteria reduce fungi on early life stages of endangered Colorado boreal toads (Anaxyrus boreas). ISME Journal, 10, 934-944.

Kurtz Z. D., Müller C. L., Miraldi E. R., Littman D. R., Blaser M. J., \& Bonneau R. A. (2015). Sparse and compositionally robust inference of microbial ecological networks. PloS Computational Biology, 11, e1004226.

Legendre L., \& Legendre P. Numerical ecology. Elsevier, Amsterdam, NL, 2012. 
Leibold M. A., \& Mikkelson G. M. (2002). Coherence, species turnover, and boundary clumping: elements of meta-community structure. Oikos, 97, 237-250.

Li H. (2015). Microbiome, metagenomics, and high-dimensional compositional data analysis. Annual Review of Statistics and Its Applications, 2, 73-94.

Little A. E., Robinson C. J., Peterson S. B., Raffa K. F., \& Handelsman J. (2008). Rules of engagement: interspecies interactions that regulate microbial communities. Annual Review of Microbiology, 62, 375-401.

Liu H., Roeder K., \& Wasserman L. (2010). Stability approach to regularization selection (StARS) for high dimensional graphical models. Advances in Neural Information Processing Systems, 23, 1432-1440.

Ma B., Wang H., Dsouza M., Lou J., He Y., Dai Z., ... Gilbert J. A. (2016). Geographic patterns of co-occurrence network topological features fro soil microbiota at continental scale in eastern China. ISME Journal, 10, 1981-1901.

Maranon E., Holligan P. M., Barciela R., Gonzalez N., Mourino B., Pazo M. J., \& Varela M. (2001). Patterns of phytoplankton size structure and productivity in contrasting open-ocean environments. Marine Ecology Progress Series, 216, 43-56.

Martens H. (2001). Reliable and relevant modelling of real world data: A personal account of the development of PLS Regression. Chemometrics and Intelligent Laboratory Systems, 58, 85-95.

Martinez-Garcia M., Brazel D., Poulton N. J., Swan B. K., Luesma Gomez M., Masland D., ... Stepanauskas, R. (2012). Unveiling in situ interactions between marine protists and bacteria through single cell sequencing. ISME Journal, 6, 703-707.

McMurdie P. J., \& Holmes S. (2014). Waste not, want not: why rarefying microbiome data is inadmissible. PloS Computational Biology, 10, e1003531.

Morán X. A., López-Urrutia A., Calvo-Díaz A., \& Li W. K. W. (2010). Increasing importance of small phytoplankton in a warmer ocean. Global Change Biology, 16, 1137-1144.

Ni J., Yan Q., \& Yu Y. (2013). How much metagenomic sequencing is enough to achieve a given goal? Scientific Reports, 3, 1968.

Not F., Latasa M., Marie D., Cariou T. Vaulot D., \& Simon N. (2004). A single species, Micromonas pusilla (Prasinophyceae), dominates the eukaryotic picoplankton in the western English Channel. Applied and Environmental Microbiology, 70, 4064-4072.

Özkan K., Jeppesen E., Davidson T. A., Søndergaard M., Lauridsen T. L., Bjerring R., ... Svenning J.-C. (2014). Cross-taxon congruence in lake plankton largely independent of environmental gradients. Ecology, 95, 2778-2788.

Paliy O., \& Shankar V. (2016). Application of multivariate statistical techniques in microbial ecology. Molecular Ecology, 25, 1032-1057.

Paulson J. N., Stine O. C., Bravo H. C., \& Pop M. (2013). Differential abundance analysis for microbial marker-gene surveys. Nature Methods, 10, 1200-1020.

Peralta G. (2016). Merging evolutionary history into species interaction networks. Functional Ecology, 30, 1917-1925.

Pocock M. J. O., Evans D. M., Fontaine C., Harvey M., Julliard R., McLaughlin O., ... Bohan D. A. (2016). The visualization of ecological networks, and their use as a tool for engagement, advocacy and management. Advances I Ecological Research, 54, 41-85.

Portillo M. C., Anderson S. P., \& Noah F. (2012). Temporal variability in the diversity and composition of stream bacterioplankton communities. Environmental Microbiology, 14, 2417-2428.

R Core Team (2019). R: A language and environment for statistical computing. $\mathrm{R}$ Foundation for Statistical Computing, Vienna, Australia. Retrieved from https://www.R-project.org/ 
Ramette A. (2007). Multivariate analyses in microbial ecology. FEMS Microbiology

727 Ecology, 62, 142-160.

728 Rappé M. S., \& Giovannoni S. J. (2003). The uncultured microbial majority. Annual Review

Rodrigeuz-Gironés M. A., \& Santamaría L. (2006). A new algorithm to calculate the nestednes temperature of presence-absence matrices. Journal of Biogeography, 33, 924-935.

Rooney R. C., \& Bayley S. E.. (2012). Community congruence of plants, invertebrates and birds in natural and constructed shallow open-water wetlands: Do we need to monitor multiple assemblages? Ecological Indicators, 20, 2012, 42-50.

Santi E., Maccherini S., Rocchini D., Bonini I., Brunialti G., Favilli L., ... Chiarucci A. (2010). Simple to sample: vascular plants as surrogate group in a nature reserve. Journal for Nature Conservation, 18, 2-11.

Schloss P. D., Westcott S. L., Ryabin T., Hall J. R., Hartmann M., Hollister E. B., ... Weber C. F. (2009). Introducing mothur: Open-source, platform-independent, communitysupported software for describing and comparing microbial communities. Applied and Environmental Microbiology, 75, 7537-7541.

Simon M., Jardillier L., Deschamps P., Moriera D., Restoux G., Bertolino P., \& López-García P. (2014). Complex communities of small protists and unexpected occurrence of typical marine lineages in shallow freshwater systems. Environmental Microbiology, $17,3610-3627$.

Simon M., López-García P., Deschamps P., Moreira D., Restoux G., Bertolino P., \& Jardillier L. (2015). Marked seasonality and high spatial variability of protist communities in shallow freshwater systems. ISME Journal, 9, 1941-1953.

Simpson G. L. (2009). Cocorresp: Co-correspondence analysis ordination methods. (R package version 0.3-0). (http://cran.r-project.org/package=analogue).

Spencer S. J., Tamminen M. V., Preheim S. P., Guo M. T., Briggs A. W., Brito I. L., ... Alm E. J. (2016). Massively parallel sequencing of single cells by epicPCR links functional genes with phylogenetic markers. ISME Journal, 10, 427-436.

Spiegelhalter D., Pearson M., \& Short I. (2011). Visualizing uncertainty about the future. Science, 333, 1393-1400.

Subirana L., Péquin B., Michely S., Escande M.-L., Meilland J., Derelle E., ... Grimsley N. H. (2013). Morphology, genome plasticity, and phylogeny in the genus Ostreococcus reveal a cryptic species, 0 . mediterraneus sp. nov. (Mamiellales, Mamiellophyceae). Protist, 164, 643-659.

Teira E., Mourino B., Maranón E., Perez V., Pazo M. J., Serret P., ... Fernández, E. (2005). Variability of chlorophyll and primary production in the Eastern North Atlantic Subtropical Gyre: potential factors affecting phytoplankton activity. Deep-Sea Research Part I, 52, 569-588.

ter Braak C. J. F., \& Schaffers A. P. (2004). Co-correspondence analysis: a new ordination method to relate two community compositions. Ecology, 85, 834-846.

ter Braak C. J. F. (1990). Interpreting canonical correlation analysis through biplots of structural correlations and weights. Psychometrika, 55, 519-531.

Tipton L., Müller C. L., Kurtz Z. D., Huang L., Kleerup E., Morris A., ... Ghedin E. (2018). Fungi stabilize connectivity in the lung and skin microbial ecosystems. Microbiome, 6 , 12.

Ulrich W., \& Gotelli N. J. (2007). Null model analysis of species nestedness patterns. Ecology, 88, 1824-1831. 
Vacher C., Tamaddoni-Nezhad A., Kamenova S., Peyrard N., Moalic Y., Sabbadin R., ... Bohan, D. A. (2016). Learning ecological network from next-generation sequencing data. Advances in Ecological Research, 54, 1-39.

Vaulot D., Lepère C., Toulza E., De la Iglesia R., Poulain J., Gaboyer F., ... Piganeau G. (2012). Metagenomes of the Picolaga Bathycoccus from the Chile coastal upwelling. PLoS One, 7, e39648.

Viprey M., Guillou L., Ferréol M., \& Vaulot D. (2008). Wide genetic diversity of picoplanktonic green algae (Chloroplastida) in the Mediterranean Sea uncovered by a phylum-biased PCR approach. Environmental Microbiology, 10, 1804-1822.

Virtanen R., Ilmonen J., Paasivirta L., \& Muotka T. (2009). Community concordance between bryophyte and insect assemblages in boreal springs: A broad-scale study in isolated habitats. Freshwater Biology, 54, 1651-1662.

Webster J. R., \& Benfield E.F. (1986). Vascular plant breakdown in freshwater ecosystems. Annual Review of Ecology and Systematics, 17, 567-594.

Weiss S., Van Treuren W., Lozupone C., Faust K., Friedman J., Deng Y., ...Knight R. (2016). Correlation detection strategies in microbial data sets vary widely in sensitivity and precision. ISME Journal, 10, 1669-1681.

Westgate M. J., Barton P. S., Lane P. W., \& Lindenmayer D. B. (2014). Global meta-analysis reveals low consistency of biodiversity congruence relationships. Nature Communications, 5, 3899.

Wisz M. S., Pottier J., Kissling W. D., Pellissier L., Lenoir J., Damgaard C. F., ... Svenning J.C. (2013). The role of biotic interactions in shaping distributions and realised assemblages of species: implications for species distribution modelling. Biological Reviews, 88, 15-30.

Wolters, Bengtsson, \& Zaitsev. (2006). Relationship among the species richness of different taxa. Ecology, 87, 1886-1895.

Worden A. Z., Nolan J. K., \& Palenik B. (2004). Assessing the dynamics and ecology of marine picophytoplankton: the importance of the eukaryotic component. Limnology and Oceanography, 49, 168-179.

Wu W., Huang B., \& Zhong C. (2013). Photosynthetic picoeukaryote assemblages in the South China Sea from the Pearl River estuary to the SEATS station. Aquatic Microbial Ecology,71, 271-284.

Xue Y., Chen H., Yang J. R., Liu M., Huang B., \& Yang J. (2018). Distinct patterns and processes of abundant and rare eukaryotic plankton communities following a reservoir cyanobacterial bloom. ISME Journal, 12, 2263-2277.

Yang C., Li Y., Zhou Y., Lei X., Zheng W., Tian Y., ... Zheng T. (2016). A comprehensive insight into functional profiles of free-living microbial community responses to toxic Akshiwo sanguinea bloom. Scientific Reports, 6, 34645.

Zhu F., Massana R., Not F., Marie D., \& Vaulot D. (2005). Mapping of picoeukaryotes in marine ecosystems with quantitative PCR of the 18S rRNA gene. FEMS Microbiology Ecology, 52, 79-92.

Zimmerman N., Izard J., Klatt C., Zhou J., \& AronsonE. (2014). The unseen world: environmental microbial sequencing and identification methods for ecologists. Frontiers in Ecology and the Environment, 12, 224-231.

Zinger L., Gobet A., \& Pommier T. (2011). Two decades of describing the unseen majority of aquatic microbial diversity. Molecular Ecology, 21, 1878-1896.

\section{Data accessibility statement}


822 Data and R scripts to reproduce the different analyses of the case study 1 and the case

823 study 2 Mamiellophyceae/Prasinovirus system-are available online in the Appendix 1as 824 additional supporting information.

\section{Author contributions}

827 Y.D. and S.D. supervised the project; B.A. performed all the statistical analyses; C.J.F.B.

828 contributed to mathematical development of the method; H.L. contributed to collecting 829 and genotyping the biological materials of microalgae and viruses; B.A. wrote the first 830 draft of the manuscript; B.A., C.J.F.B., Y.D., and S.D. commented and approved the final 831 version of the manuscript.

832

\section{Supporting information}

834 Additional supporting information may be found online in the Supporting Information 835 section at the end of the article. 
838

839

840

841

842

843

844

845

846

847

848

849
Figure 1. Ordination biplots of - the case study 1 , representing positions of sites (open diamond) and species (solid triangle) on the axis $1 \times$ axis 2 factorial plan of the symmetric co-correspondence analysis. (a) Biplot for the heterotrophic microbial eukaryotes and (b) biplot for the autotrophic microbial eukaryotes-OTUs obtained from symmetric co correspondenee analysis. EV: Etang des Vallées, LC: La Claye, GB: Mare Gabard, SR: Saint Robert, RSA: Ru Sainte Anne. Heterotrophic and autotrophic microbial eukaryotes OTUs are colored according to the phylogenetic group they belong to. " $d$ " indicates the mesh of the grid.

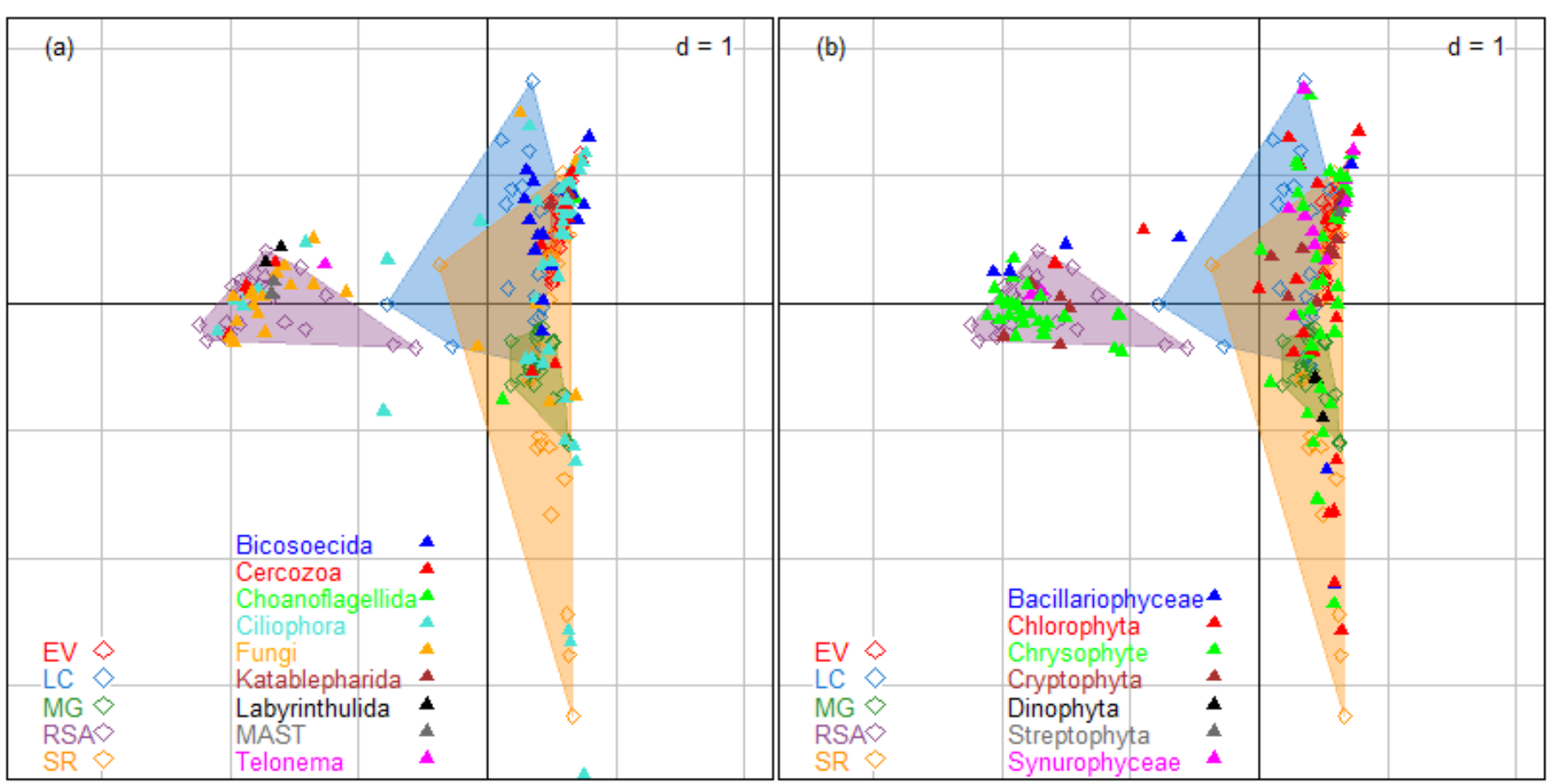


Figure 2. Heatmap of the case study 1, representing the association network between $\underline{\text { the }}$ f heterotrophic and autotrophic microbial eukaryotes $\underline{(a)}$ before (a) and (b) after (b) the reordering the position of each species in the network according to their network from the speeies scores on the first axis of symmetric co-correspondence analysis. Bar plots of the relative abundance of (c) autotrophic microbial eukaryotes and (d) heteretrophic microbial eukaryotes. Each OTU is represented by a vertical line partitioned into segments corresponding to its relative abundance in one of five sites. EV: Etang des Vallées, LC: La Claye, GB: Mare Gabard, SR: Saint Robert, RSA: Ru Sainte Anne.
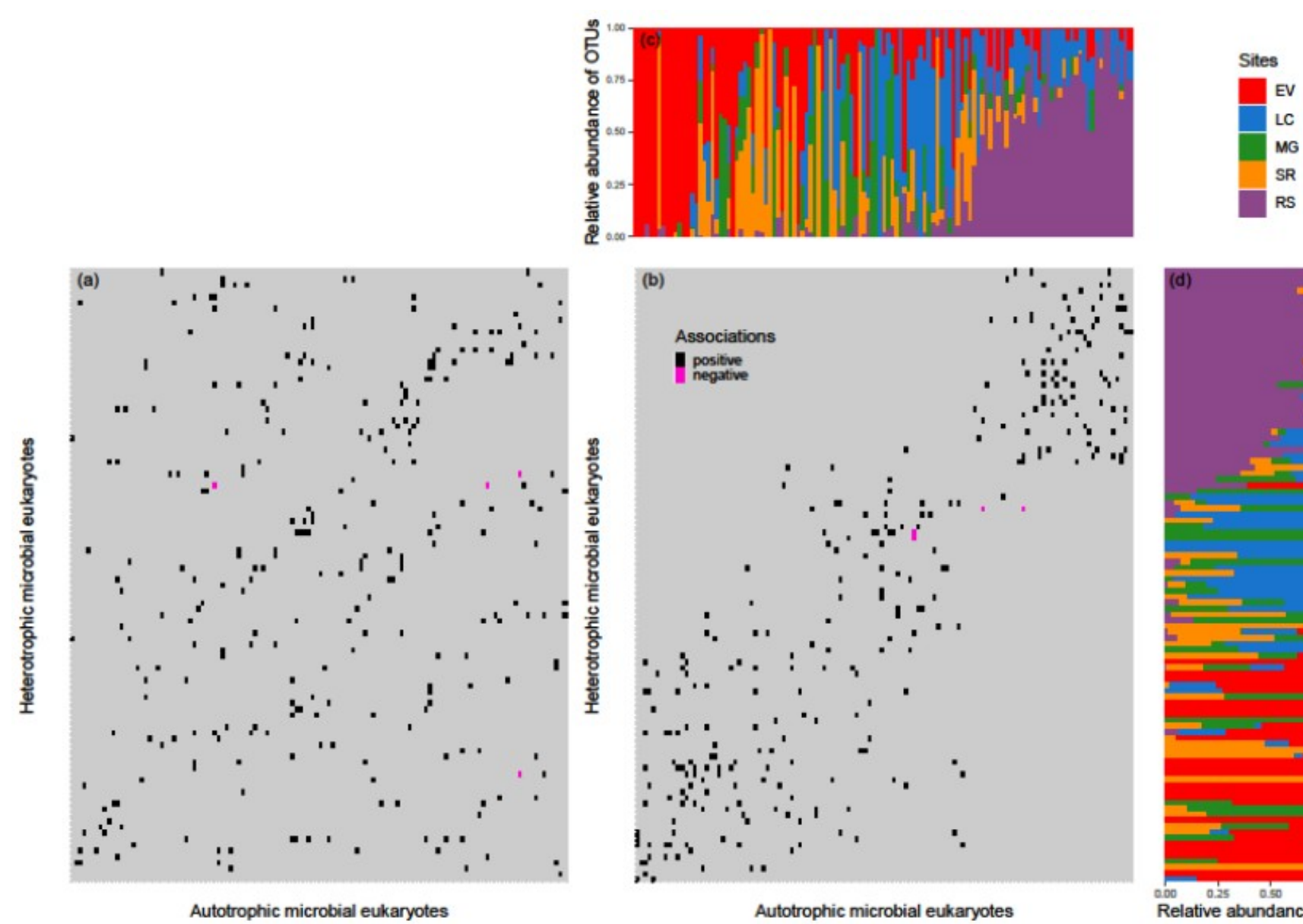

862
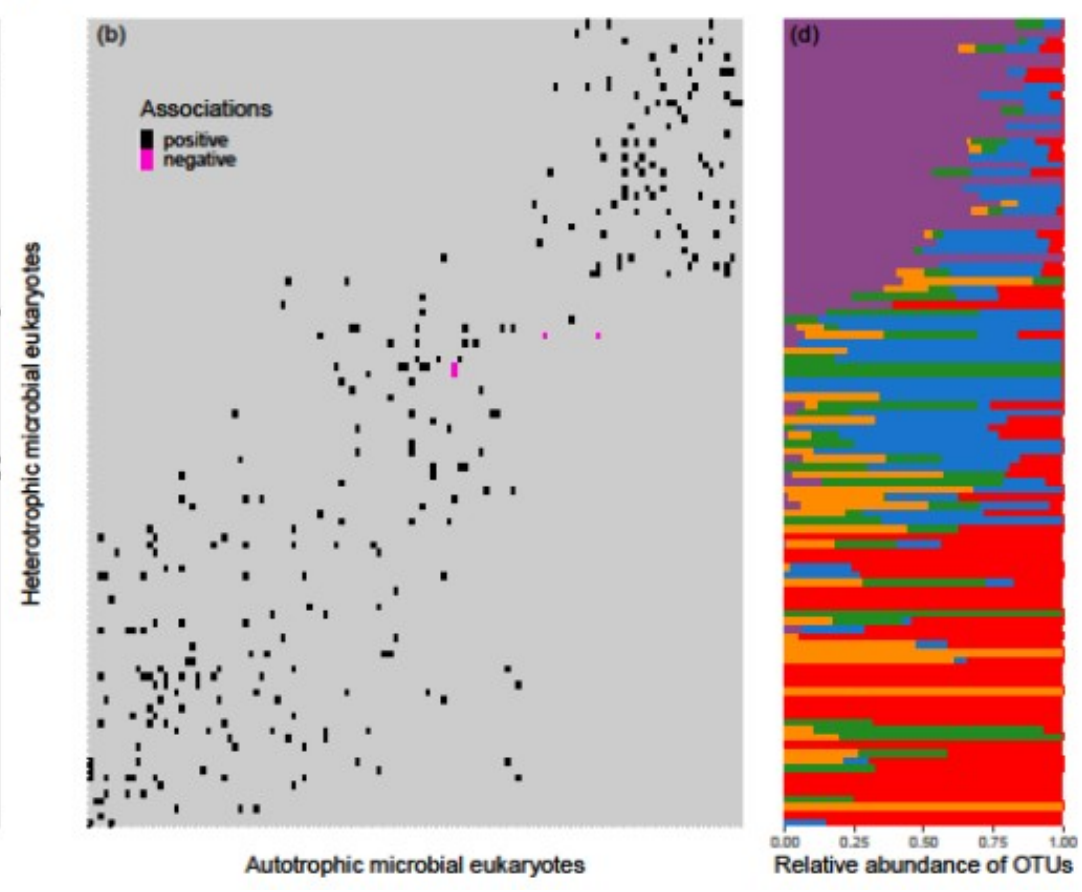
Figure 3. Ordination biplots of, concerning the case study 2, efrepresenting the positions of sites (open diamond) and species (solid triangle) on the axis $1 \times$ axis 2 factorial plan of the predictive co-correspondence analysis. (a) Biplot for the Mamiellophyceae and (b) biplot for the Prasinovirus-OTUs obtained from predietiveeo-correspondence analysis. LB: coastal site in Leucate lagoon, LA: site at the level of the Grau in Leucate lagoon, SA: coastal site, MA: open-sea site. Microalgae and virus

873

874

875

876

877

878

879

880

881

882

883

884 OTUs are colored according to the phylogenetic group they belong to. BpV: Bathycoccus viruses, MpV: Micromonas viruses, OtV: Ostreococcus viruses. "d" indicates the mesh of the grid.

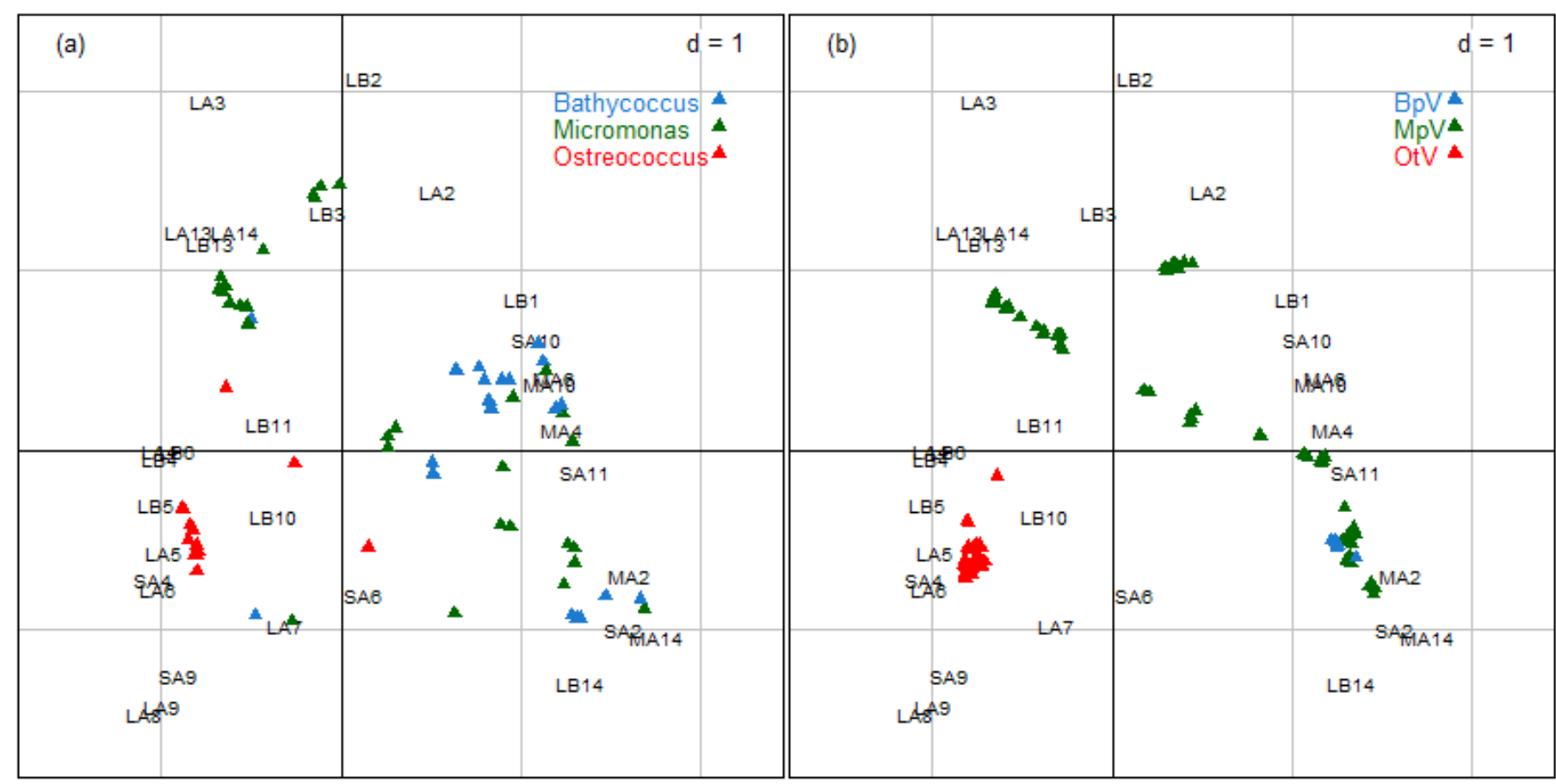

Figure 3. Heatmap of heterotrophic and autotrophie mierobial eukaryotes before (a) and after (b) the reordering the network from the species seores on the first axis of symmetrie eo-correspondenee analysis. Bar plots of the relative abundanee of (e) autotrophic microbial eukaryotes and (d) heteretrophic mierobial eukaryotes. EachOTU is represented by a vertical line partitioned into segments corresponding to its relative abundanee in one of five sites. EV: Etang des Vallées, LC: La Claye, GB: MareGabard, SR: Saint Robert, RSA: Ru Sainte Anne. 
Figure 4. Heatmap of the case study 2 , representing the microalgae-viruses

(Mamiellophycaea/Prasinovirus) association network (a) before (a) and (b) after (b) the reordering the position of each species in the network according to their network from the speeies scores on the first axis of predictive co-correspondence analysis. Bar plots of the relative abundance of (c) microalgae and (d) viruses. Each OTU is

890 represented by a vertical line partitioned into segments corresponding to its relative abundance in one of four sites. LA: site at the level of the Grau in Leucate lagoon, LB: coastal site in Leucate lagoon, SA: coastal site, MA: open-sea site.
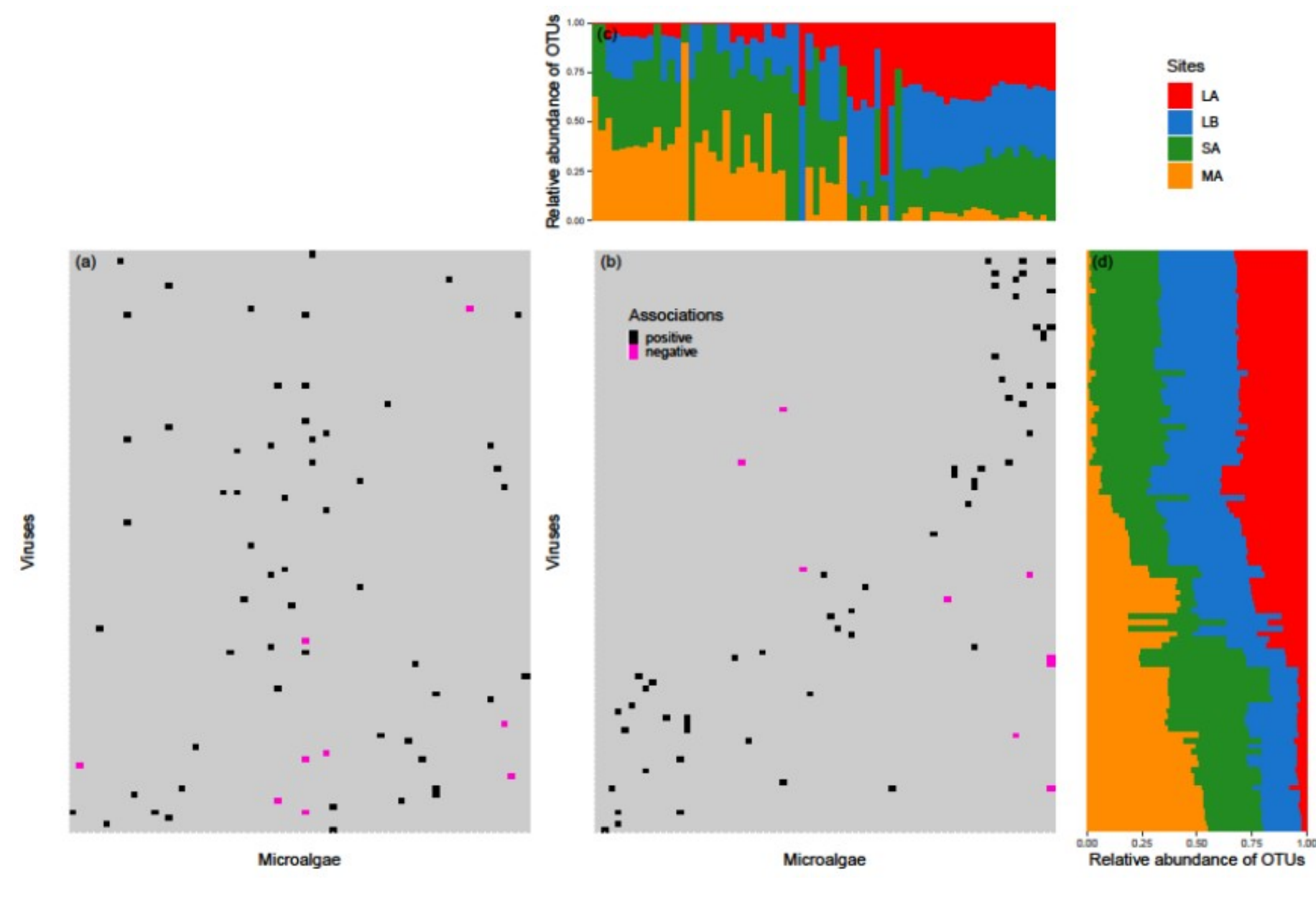